\title{
Predictive value of upper-limb accelerometry in acute stroke with hemiparesis
}

\author{
Nick Gebruers, PhD, PT; ${ }^{1-3^{*}}$ Steven Truijen, PhD, MSc; ${ }^{1-3}$ Sebastiaan Engelborghs, PhD, MD; ${ }^{2,4}$ Peter P. \\ De Deyn, PhD, MD $^{1-2,4-5}$ \\ ${ }^{1}$ Department of Health Care Sciences, University College of Antwerp, Merksem, Belgium; ${ }^{2}$ Department of Neurology \\ and Memory Clinic, Hospital Network Antwerp, Antwerp, Belgium; ${ }^{3}$ Department of Rehabilitation Sciences and Phys- \\ iotherapy, University of Antwerp, Antwerp, Belgium; ${ }^{4}$ Laboratory of Neurochemistry and Behaviour, Institute Born- \\ Bunge, University of Antwerp, Antwerp, Belgium; ${ }^{5}$ Department of Neurology and Alzheimer Research Center, Univer- \\ sity Medical Center Groningen, Groningen, the Netherlands
}

\begin{abstract}
Few studies have investigated how well early activity measurements by accelerometers predict recovery after stroke. First, we assessed the predictive value of accelerometer-based measurements of upper-limb activity in patients with acute stroke with a hemiplegic arm. Second, we established the difference in arm activity between hospitalized stroke and nonstroke patients. In total, 129 patients with acute stroke and 19 controls participated. Activity of the upper limbs was monitored for $48 \mathrm{~h}$, and these data were used to determine the predictive value of the activity variables compared with the modified Rankin Scale (mRS), which was assessed at 3 mo poststroke onset. The sensitivity and specificity in relation to the mRS were 0.80 and 0.77 , respectively, for the activity of impaired arm (AIA) and 0.85 and 0.75, respectively, for the ratio variable calculated by dividing the AIA by the activity of the nonimpaired arm. The corresponding cutoff values were 597,546 counts for AIA and 0.33 for the ratio. The predictive value of AIA combined with age was $85 \%$ to the disability status defined as an mRS score of 2 or less.
\end{abstract}

Key words: accelerometry, activity measure, ambulatory monitoring, hemiparesis, modified Rankin Scale, paresis, prediction, recovery, stroke, upper limb.

\section{INTRODUCTION}

Accelerometry was developed to monitor activity based on the measurement of accelerations made by the patient or person of interest [1]. It has several advantages such as the ability to record continuously for days or even weeks, no known first night effect, and the possibility to measure patients in their own environment if needed [2].

Only recently were accelerometry-based measurements introduced in clinical stroke research. The clinometric properties of accelerometry to measure activity in patients with stroke are promising, especially the validity and reliability of accelerometry to measure the activity of

\footnotetext{
Abbreviations: AIA = activity of impaired arm, AMR $=$ arm movement ratio, ANIA = activity of nonimpaired arm, ANOVA $=$ analysis of variance, ARAT $=$ Arm Research Action Test, AUC = area under curve, EHI = Edinburgh Handedness Inventory, FMA = Fugl-Meyer Assessment, MRI = magnetic resonance imaging, $\mathrm{mRS}=$ modified Rankin Scale, $\mathrm{PIM}=$ proportional integrated mode

*Address all correspondence to Nick Gebruers, PhD, PT; Department of Rehabilitation Sciences and Physiotherapy, Faculty of Medicine and Health Sciences, University of Antwerp, Universiteitsplein 1, 2610 Antwerp, Belgium; fax: 32-3-265-25-01. Email: nick.gebruers@uantwerpen.be http://dx.doi.org/10.1682/JRRD.2012.09.0166
} 
patients with stroke in the different stages, demonstrated by means of various protocols [3]. In this study, we were particularly interested in measuring the activity of the upper limbs. Uswatte et al. provided significant evidence about the validity and reliability of accelerometry to measure upper-limb activity in stroke [4-8]. Details about the clinometric properties of upper-limb accelerometrybased measurements are published elsewhere [3]. Additional information for the validity of accelerometry-based measurements taken in the acute phase of stroke came from one of our own studies [9].

However, no study, to our knowledge, has investigated the predictive value of early accelerometer measurements in acute stroke for upper-limb recovery. Otherwise, different attempts have been made to investigate the predictive value of different scales that are available to assess patients in the acute phase of stroke [10 12]. However, an often-encountered problem is that patients cannot answer reliably due to altered consciousness in the acute phase of stroke.

Therefore, we hypothesized that-

- In acute stroke, accelerometers can gather data on upper-limb use that have a predictive value for recovery.

- Hospitalized patients with acute stroke use the affected arm less than hospitalized nonstroke patients assessed by accelerometers.

The major aim of this prospective study was to investigate the predictive value of early accelerometer-based measurements of arm use in relation to the disability status. Therefore, we hypothesized that early accelerometer measurements, which can be taken independent of the patient's state of consciousness, can predict the disability status at 3 mo follow-up. A secondary aim was to compare the activity of the upper limbs of hospitalized patients with and without acute stroke.

\section{METHODS}

\section{Subjects}

Patients were eligible for inclusion in this study if they met the following criteria: diagnosis of acute $(<7 \mathrm{~d}$ after onset) stroke (World Health Organization definition and clinical examination in combination with brain computed tomography and/or magnetic resonance imaging [MRI] scan) accompanied by a hemiparesis of the upper limb (score $>0$ on National Institutes of Health Stroke Scale motor item of the upper limb). Patients with a prior stroke with incomplete motor function recovery were not included.

We included 129 patients in the study following written informed consent or consent by proxy, if applicable. The following demographic and clinical data were recorded in the Case Record Forms: medication use, medical and surgical history, length of hospital stay on the acute neurology ward, rehabilitation status (home, rehabilitation center, nursing home), age, sex, height, weight, body mass index, self-reported handedness, Edinburgh Handedness Inventory (EHI) score, and the different stroke scale scores (Fugl-Meyer Assessment [FMA] and modified Rankin Scale [mRS]). The FMA and EHI were assessed at study entry in the acute phase; the mRS was scored only at 3 mo follow-up.

We included 24 control patients based on the following criteria: (1) had been hospitalized for at least two consecutive days, (2) agreed to wear the accelerometers for $48 \mathrm{~h}$ and able to understand instructions in Dutch, (3) were within the age range of the patients with stroke (24-94 yr), and (4) had normal upper-limb functions. Mostly, control patients were hospitalized because they needed examinations that were scheduled over consecutive days. Patients were excluded from the control group if they (1) had any neurological impairment of the upper limbs, (2) had any surgery or problem influencing the normal use of the upper limbs, or (3) were bedridden.

\section{Accelerometry}

Accelerometer recordings were made using octagonal basic motion loggers (Amubulatory Monitoring Inc; Ardsley, New York). The details about the octagonal basic motion logger are described elsewhere [9]. For the current study, we recorded all data in the proportional integrated mode (PIM) with an epoch length of $1 \mathrm{~s}$. Data were exported to a personal computer and rebinned into 30 min epochs using a Java program (JBuilder version 3.0, Borland; Santa Clara, California), which summed 1,800 one-second epoch scores for each half hour. Since the recordings among the different patients did not start at the same time of day, $48 \mathrm{~h}$ data were averaged to a $24 \mathrm{~h}$ data set, starting at the same time. Before averaging the data, all periods with no activity were matched to the event log and deleted if the accelerometer was indeed removed during that period. The amount of activity is presented as counts. Ratios (activity of impaired arm [AIA]/activity of nonimpaired arm [ANIA]) were calculated by dividing the activity counts of the affected upper 
limb (AIA) by the activity counts of the unaffected side (ANIA), which is in analogy with other studies [4-6,9]. An important reason to calculate the ratio variable is to avoid the influence of unintentional movements.

The accelerometer recordings of the patients with stroke started within $1 \mathrm{wk}$ (median: $1 \mathrm{~d}$ ) after stroke onset. Subjects wore the motion loggers continuously on both wrists for $48 \mathrm{~h}$ and received standard care consisting of nursing, physical therapy, occupational therapy, and speech therapy, if necessary. Although the patients knew that the accelerometers measured their activity, patients were not motivated to perform additional movements. The control patients also wore the accelerometers on both wrists for $48 \mathrm{~h}$ starting at the first or second day after hospitalization. The motion loggers were removed only during showering and MRI scanning. These events were mentioned in the event log for every patient. The nonaffected arm was used as a control for the affected side in patients with stroke. For the control patients, a comparison was made between the nondominant and dominant $\operatorname{arm}($ ratio $=$ nondominant $/$ dominant $)$.

\section{Scales}

The arm section of the FMA was used to determine the motor function of the impaired arm and was administered at inclusion [9]. The FMA is a motor function questionnaire with an upper- and lower-limb section [13]. Both sections can be used together or separately. In this study, only the upper-limb section of the FMA was used because the upper limb was of interest in this study. The upper-limb section of the FMA consists of 33 items. All items are scored as an ordinal rank order. Score can be 0 (patient is unable to perform), 1 (patient is able to perform partially), or 2 (patient is able to perform normally) [14-15]. The maximum FMA score is 66. The items can be divided into categories such as reflexes, movement observation, grasp testing, and coordination [14].

At 3 mo follow-up, the mRS was scored. The mRS is a measure of global disability that quantifies disability as an ordinal rank order. Hierarchical grading is possible from 0 (no symptoms) to 5 (severe disability); additionally, a score 6 (death) can be added [16]. The mRS is widely applied in research as an outcome or end-point measure. It has good clinometric properties [17]. However, the interrater reliability remains a subject of discussion even after the introduction of a structured interview to score the mRS $[16,18]$. Therefore, all mRS scores were taken by the same rater in this study.

\section{Statistical Analyses}

Demographics for the patients with stroke as well as the control sample are presented using descriptive statistics. An independent sample $t$-test and a chi-square statistic were used to demonstrate the result of the matching procedures as well as the difference in activity variables between controls and patients with stroke. An independent sample $t$-test was also used to compare the activity variables between patients with a hemiparesis of the dominant arm and patients with a hemiparesis of the nondominant arm.

A cutoff value was used to divide the patients with stroke into two groups. For the FMA upper-limb section, we used a cutoff score of $\geq 45$ to divide the patients with stroke into two groups [9]. These two groups were compared with the control group by means of a one-way analysis of variance (ANOVA) with a Bonferroni post hoc analysis. Correlations between the accelerometer data (PIM) and stroke scales were calculated using a Spearman correlation test because all mRS and FMA items are scored as an ordinal rank order.

Next, the predictive value of the activity variables was calculated using a logistic regression model. Receiver operating curves were used to define sensitivity and specificity values for the activity variables with respect to the dichotomization of the mRS. The mRS scores were dichotomized using a score of $\leq 2$, because a score of 2 or less means that a patients is at least able to look after his or her own affairs without assistance. This cutoff value is also documented in other studies [19-22].

\section{RESULTS}

We included 24 control patients and 129 patients with stroke. Data for five of the control patients were removed from the analyses due to accelerometer malfunction. The demographic variables of these 5 patients were not significantly different from the 19 remaining control patients. Table 1 presents the demographic data of both groups, as well as the details of the matching procedure. We found no statistical difference between the activity variables of patients with hemiparesis of the dominant arm and hemiparesis of the nondominant arm. Therefore, we compared the control group with the whole group $(n=129)$ of patients with stroke. Table 2 presents these results in detail. 
JRRD, Volume 50, Number 8, 2013

Table 1.

Demographic characteristics of study participants and matching statistics.

\begin{tabular}{|c|c|c|c|}
\hline Variable & $\begin{array}{l}\text { Patients with Acute Stroke } \\
\text { ( } n=129)\end{array}$ & $\begin{array}{l}\text { Controls } \\
(n=19)\end{array}$ & $\begin{array}{c}\text { Independent Sample } \\
t \text {-Test } p \text {-Value }\end{array}$ \\
\hline$\overline{\text { Age, yr (mean } \pm \text { SD) }}$ & $74.0 \pm 11.4$ & $71.0 \pm 14.0$ & 0.29 \\
\hline Height, m (mean \pm SD) & $1.69 \pm 0.09^{*}$ & $1.68 \pm 0.08^{\dagger}$ & 0.46 \\
\hline Body Mass Index $($ mean \pm SD) & $26.6 \pm 4.2^{*}$ & $28.3 \pm 5.4^{\dagger}$ & 0.13 \\
\hline Sex, $n(\%)$ & & & $0.51^{\ddagger}$ \\
\hline Type of Stroke, $n(\%)$ & & & - \\
\hline Ischemic & $117(91)$ & - & \\
\hline Hemorraghic & $12(9)$ & - & \\
\hline Side of Paresis, $n(\%)$ & & & - \\
\hline Right & $65(50)$ & - & \\
\hline Nondominant & $70(54)$ & - & \\
\hline $\begin{array}{l}{ }^{*} n=121 . \\
{ }^{\dagger} n=17 . \\
{ }^{\ddagger} \text { Chi-square statistic. } \\
\text { SD = standard deviation. }\end{array}$ & & & \\
\hline
\end{tabular}

Table 2.

Comparison of activity variables between controls and patients with stroke. Both groups are compared in total (independent sample $t$-test) and then patients with stroke are divided into two groups based on Fugl-Meyer Assessment (FMA) $\geq 45$ dichotomization (one-way analysis of variance [ANOVA]).

\begin{tabular}{|c|c|c|c|c|c|c|}
\hline \multirow{2}{*}{ Variable } & \multicolumn{6}{|c|}{ Independent Sample $t$-Test } \\
\hline & \multicolumn{2}{|c|}{ Controls $(n=19)$} & \multicolumn{2}{|c|}{ Patients with Stroke $(n=129)$} & \multicolumn{2}{|c|}{$p$-Value } \\
\hline AIA Count (mean \pm SD) & \multicolumn{2}{|c|}{$1,832,133 \pm 735,323$} & \multicolumn{2}{|c|}{$870,718 \pm 638,490$} & \multicolumn{2}{|c|}{$<0.001$} \\
\hline \multirow{3}{*}{ Variable } & \multicolumn{6}{|c|}{ One-Way ANOVA with Post Hoc Bonferroni Analyses } \\
\hline & \multirow{2}{*}{$\begin{array}{l}\text { Control } \\
(n=19)\end{array}$} & \multirow{2}{*}{$\begin{array}{c}\text { Group } 1 \\
(\text { FMA }<45, n=87)\end{array}$} & \multirow{2}{*}{$\begin{array}{c}\text { Group } 2 \\
(\text { FMA } \geq 45, n=42)\end{array}$} & \multicolumn{3}{|c|}{ p-Value } \\
\hline & & & & $\begin{array}{c}\text { Control vs } \\
\text { Group } 1\end{array}$ & $\begin{array}{c}\text { Control vs } \\
\text { Group } 2\end{array}$ & $\begin{array}{l}\text { Group } 1 \text { vs } \\
\text { Group } 2\end{array}$ \\
\hline Ratio (mean \pm SD) & $1.05 \pm 0.25$ & $0.48 \pm 0.83$ & $0.75 \pm 0.28$ & $<0.05$ & 0.30 & 0.94 \\
\hline AIA Count (mean \pm SD) & $1,832,133 \pm 735,323$ & $572,090 \pm 355,526$ & $1,489,304 \pm 652,978$ & $<0.001$ & 0.05 & $<0.001$ \\
\hline ANIA Count (mean \pm SD) & $1,879,431 \pm 736,002$ & 1,797,364 \pm 955,012 & $2,035,471 \pm 693,970$ & 1.00 & 1.00 & 0.43 \\
\hline
\end{tabular}

The relationship between the activity measured by accelerometry in the acute phase and the outcome after 3 mo represented by the mRS score was the primary focus in the current study. Since a score of 6 on the mRS means that the patient has died, we excluded these patients $(n=22)$ for further analyses because several $(n=$ 8) patients did not die of stroke-related causes, deforming the activity scores.
We calculated Spearman correlations between the activity variables and stroke scales. Table 3 presents these correlations. Since only the mRS was scored at 3 mo follow-up, the relation between activity variables and the mRS was visualized by means of a box-plot graph (Figure).

The Figure displays a clear relation between activity measured in the acute phase and the outcome (mRS) at 
Table 3.

Spearman $\rho$ correlations between activity variables and stroke scales (all $p<0.01$ ).

\begin{tabular}{lccl}
\hline Activity Variable & mRS & FMA & NIHSS \\
\hline AIA & -0.59 & 0.70 & -0.68 \\
Ratio & -0.48 & 0.60 & -0.51
\end{tabular}

AIA = activity of impaired arm, FMA = Fugl-Meyer Assessment, mRS = modified Rankin Scale, NIHSS = National Institutes of Health Stroke Scale.

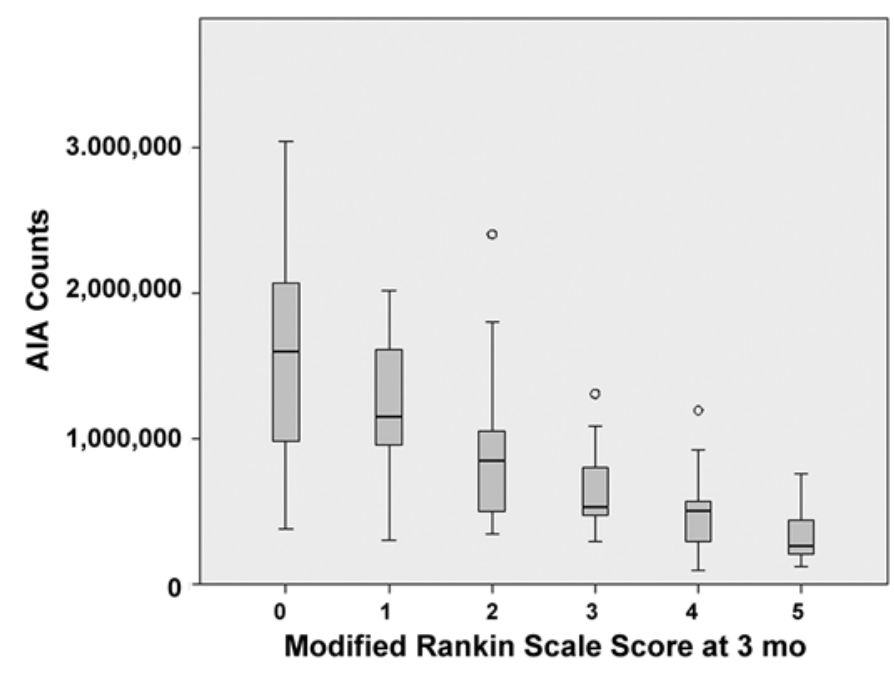

Figure.

Relation between activity of impaired arm (AIA) during acute phase of stroke and modified Rankin Scale score at 3 mo follow-up. Circles represent outliers.

3 mo. We therefore further determined the predictive value of acute activity measurements. The results demonstrated the highest sensitivity and specificity for the ratio and AIA compared with the mRS dichotomization based on a cutoff value of $\leq 2$. The sensitivity and specificity for the ratio and AIA are, respectively, 0.85 and 0.75 (area under curve [AUC] $=0.84$ ) and 0.80 and 0.77 (AUC $=0.87$ ). The corresponding cutoff values are 0.33 and 597,546 counts for ratio and AIA, respectively. Next, the predictive value was calculated by means of a logistic regression. A predictive value of 85 percent was demonstrated for the AIA in combination with age.

\section{DISCUSSION}

The major goal was to investigate the predictive value of early accelerometer-based measurements of upper-limb activity in patients with upper-limb paresis caused by stroke. The results clearly demonstrated that both the ratio, calculated as AIA/ANIA, and the AIA variable have a good sensitivity and specificity in relation to the mRS at 3 mo follow-up. Relevant cutoff values were calculated. Additionally, the AIA in combination with age has the best predictive value (85\%) in relation to the mRS. These findings indicated that younger patients with a fair amount of arm use have a better prognosis of reaching an mRS score of $\leq 2$ at 3 mo after stroke onset. Therefore, the acute accelerometer data from the upper limb can be used as a clinical predictor of recovery. In scientific literature, other predictors of upper-limb recovery can be found, as demonstrated in different reviews [10-12]. Chen and Winstein documented 85 predictors of upper-limb recovery. In the acute stage of stroke, it seems that motor-evoked potentials, transcranial motor stimulation, and a neurophysiologic evaluation have the best predictive value [11]. Since we were especially interested in the recovery of the upper limb, we were more interested in predictors of motor capability by means of performance-based measures (e.g., FMA, Arm Research Action Test [ARAT]). These tests are often used by physical therapists, but the cooperation of the patient is essential. Since in the acute stage of stroke cooperation can be hampered due to consciousness problems, we investigated the predictive value of accelerometry-based measures of upper-limb activity-a measurement that is independent of a patient's consciousness status. As demonstrated by our results, accelerometry of the upper limbs can generate a meaningful predictor in relation to the mRS. Nijland et al. demonstrated that the ability of finger extension and shoulder abduction within $72 \mathrm{~h}$ after stroke onset gave a probability of 98 percent to regain some dexterity measured by the ARAT [23]. Dexterity was defined as a score of $\geq 10$ on the ARAT. This leaves the question of whether a score of 10 is a meaningful recovery for the patient since the maximum score on the ARAT is 57 . We believe that a score of $\leq 2$ on the mRS is clinically more interesting to report to the patient since a score of $\leq 2$ on the mRS indicates that a patient will be able to look after his or her affairs without any assistance in daily life.

In addition to our primary aim, we also investigated the differences in upper-limb activity among hospitalized stroke and nonstroke patients. Although patients admitted to a hospital are bound by the strict hospital regime, we hypothesized that there would still be a difference in arm 
use between patients with a motor impairment of the arm after stroke compared with nonstroke patients with normal use of both arms. On one hand, it was clearly demonstrated that the paretic arm is used significantly less than the nondominant arm of the controls. A significant difference was also demonstrated for the ratio variable between patients with stroke and controls. On the other hand, no differences were found between the use of the nonparetic arm and the use of the dominant arm of controls. Additionally, no differences between controls and patients with stroke were found concerning the nonparetic or dominant arm use when the cutoff value $(\geq 45)$ for the FMA was used to define two groups of patients with stroke (see one-way ANOVA, Table 2).

Our results supplement the information of Lang et al., who investigated upper-limb activity in a rehabilitation center, and Thrane et al., who investigated patients with acute stroke albeit without a control group [24-25]. All studies, current one included, used the protocol presented by Uswatte et al. [4-6]. Lang et al. reported arm use in patients with stroke who resided in a rehabilitation center compared with an age-matched control group $(n=10)$. On average, these patients were included $9.3 \pm 4.2 \mathrm{~d}$ after stroke (mean \pm standard deviation). The results demonstrated that patients with stroke used their affected arm significantly less than control subjects. Since we did not report the amount of arm use in hours in our own study, we recalculated the results of Lang et al., demonstrating a ratio of 0.97 for the controls and 0.55 for the patients with stroke. These ratios are comparable with the ratios found in the current study of 1.05 and 0.57 for controls and patients with stroke, respectively. It seems that comparable results can be obtained even earlier in the poststroke phase because we have included our patients within $7 \mathrm{~d}$ after stroke (median: $1 \mathrm{~d}$, range: 1-6 d).

Thrane et al. demonstrated that patients $(n=31)$ with stroke used their affected arm and unaffected arm for $3.0 \pm 1.7$ and $4.5 \pm 1.7 \mathrm{~h} / \mathrm{d}$, respectively [25]. The decreased amount of arm use of the unaffected arm compared with the results of Lang et al. is striking. Thrane et al. also calculated a ratio (arm movement ratio [AMR]), which was calculated differently from our own ratio variable. The AMR was calculated by dividing the amount of unaffected arm use by the amount of affected arm use. This generates a high ratio for more impaired patients with stroke and a lower ratio for patients with stroke who are less affected. Therefore, the correlation between AMR and the FMA is $-0.85(p<0.001)$ [25]. This corre- lation is higher than the correlation found in the current study ( $r=0.60, p<0.001$ ) and higher than the correlation ( $r=0.54, p<0.001)$ we found in earlier research [9]. Although some differences in methodology exist, our study and the discussed articles clearly demonstrated the usefulness of accelerometers to measure the activity of the upper limbs in patients with stroke.

The results of our study can help to define the rehabilitation programs of patients with stroke. The rehabilitation might change due to early knowledge of the probable outcome. Another possibility for the use of our current results is that accelerometry can be used to select patients in an early phase to participate in novel treatment studies aimed at recovery of arm function. Undoubtedly, this needs to be established in future research.

\section{CONCLUSIONS}

The amount of arm use in patients with stroke presented as a ratio or AIA demonstrated good sensitivity and specificity in relation to the disability status (mRS) at $3 \mathrm{mo}$ and has a good clinical predictive value. Disability status defined as an mRS score of $\leq 2$ can be predicted correctly for 85 percent of the patients using the AIA variable and the age of the patient.

Additional information was provided through the use of accelerometry to measure upper-limb activity after stroke. Compared with hospitalized nonstroke patients, patients with stroke used their impaired arm significantly less, but not their unaffected arm.

\section{ACKNOWLEDGMENTS}

Author Contributions:

Study concept and design: N. Gebruers, S. Truijen, S. Engelborghs, P. P. De Deyn.

Acquisition of data: N. Gebruers.

Analysis and interpretation of data: N. Gebruers, S. Truijen, S. Engelborghs, P. P. De Deyn.

Drafting of manuscript: N. Gebruers, S. Truijen, S. Engelborghs, P. P. De Deyn.

Statistical analysis: N. Gebruers, S. Truijen.

Obtained funding: N. Gebruers.

Administrative, technical, or material support: P. P. De Deyn. Study supervision: N. Gebruers.

Financial Disclosures: The authors have declared that no competing interests exist.

Funding/Support: This material was based on work supported by Artesis University College Antwerp (grant G817). 
Institutional Review: The study protocol was approved by the local institutional review board, CME ZNA Middelheim (approval no. 2591). Written consent was obtained from all included individuals.

Participant Follow-Up: The authors have no plans to notify the study subjects of the publication of this article because of a lack of contact information.

\section{REFERENCES}

1. Chen KY, Bassett DR Jr. The technology of accelerometrybased activity monitors: Current and future. Med Sci Sports Exerc. 2005;37(11 Suppl):S490-500.

[PMID:16294112] http://dx.doi.org/10.1249/01.mss.0000185571.49104.82

2. Ancoli-Israel S, Cole R, Alessi C, Chambers M, Moorcroft W, Pollak CP. The role of actigraphy in the study of sleep and circadian rhythms. Sleep. 2003;26(3):342-92. [PMID:12749557]

3. Gebruers N, Vanroy C, Truijen S, Engelborghs S, De Deyn PP. Monitoring of physical activity after stroke: A systematic review of accelerometry-based measures. Arch Phys Med Rehabil. 2010;91(2):288-97. [PMID:20159136] http://dx.doi.org/10.1016/j.apmr.2009.10.025

4. Uswatte G, Foo WL, Olmstead H, Lopez K, Holand A, Simms LB. Ambulatory monitoring of arm movement using accelerometry: An objective measure of upperextremity rehabilitation in persons with chronic stroke. Arch Phys Med Rehabil. 2005;86(7):1498-1501.

[PMID:16003690]

http://dx.doi.org/10.1016/j.apmr.2005.01.010

5. Uswatte G, Giuliani C, Winstein C, Zeringue A, Hobbs L, Wolf SL. Validity of accelerometry for monitoring realworld arm activity in patients with subacute stroke: Evidence from the extremity constraint-induced therapy evaluation trial. Arch Phys Med Rehabil. 2006;87(10):1340-45.

[PMID:17023243]

http://dx.doi.org/10.1016/j.apmr.2006.06.006

6. Uswatte G, Miltner WH, Foo B, Varma M, Moran S, Taub E. Objective measurement of functional upper-extremity movement using accelerometer recordings transformed with a threshold filter. Stroke. 2000;31(3):662-67.

[PMID:10700501]

http://dx.doi.org/10.1161/01.STR.31.3.662

7. Uswatte G, Taub E, Morris D, Light K, Thompson PA. The Motor Activity Log-28: Assessing daily use of the hemiparetic arm after stroke. Neurology. 2006;67(7):1189-94.

[PMID:17030751]

http://dx.doi.org/10.1212/01.wnl.0000238164.90657.c2

8. Uswatte G, Taub E, Morris D, Vignolo M, McCulloch K. Reliability and validity of the upper-extremity Motor Activity Log-14 for measuring real-world arm use. Stroke.
2005;36(11):2493-96. [PMID:16224078]

http://dx.doi.org/10.1161/01.STR.0000185928.90848.2e

9. Gebruers N, Truijen S, Engelborghs S, Nagels G, Brouns R, De Deyn PP. Actigraphic measurement of motor deficits in acute ischemic stroke. Cerebrovasc Dis. 2008;26(5):533-40. [PMID:18836264] http://dx.doi.org/10.1159/000160210

10. Stinear C. Prediction of recovery of motor function after stroke. Lancet Neurol. 2010;9(12):1228-32.

[PMID:21035399]

http://dx.doi.org/10.1016/S1474-4422(10)70247-7

11. Chen SY, Winstein CJ. A systematic review of voluntary arm recovery in hemiparetic stroke: Critical predictors for meaningful outcomes using the International Classification of Functioning, Disability, and Health. J Neurol Phys Ther. 2009;33(1):2-13. [PMID:19265766] http://dx.doi.org/10.1097/NPT.0b013e318198a010

12. Hendricks HT, van Limbeek J, Geurts AC, Zwarts MJ. Motor recovery after stroke: A systematic review of the literature. Arch Phys Med Rehabil. 2002;83(11):1629-37.

[PMID:12422337]

http://dx.doi.org/10.1053/apmr.2002.35473

13. Fugl-Meyer AR, Jääskö L, Leyman I, Olsson S, Steglind S. The post-stroke hemiplegic patient. 1. A method for evaluation of physical performance. Scand J Rehabil Med. 1975;7(1):13-31. [PMID:1135616]

14. Deakin A, Hill H, Pomeroy VM. Rough guide to the FuglMeyer Assessment: Upper limb section. Physiotherapy. 2003;89(12):751-63. http://dx.doi.org/10.1016/S0031-9406(05)60502-0

15. Gladstone DJ, Danells CJ, Black SE. The Fugl-Meyer Assessment of motor recovery after stroke: A critical review of its measurement properties. Neurorehabil Neural Repair. 2002;16(3):232-40. [PMID:12234086] http://dx.doi.org/10.1177/154596802401105171

16. Quinn TJ, Dawson J, Walters MR, Lees KR. Exploring the reliability of the modified Rankin Scale. Stroke. 2009; 40(3):762-66. [PMID:19131664] http://dx.doi.org/10.1161/STROKEAHA.108.522516

17. Banks JL, Marotta CA. Outcomes validity and reliability of the modified Rankin Scale: implications for stroke clinical trials: a literature review and synthesis. Stroke. 2007;38(3): 1091-96. [PMID:17272767] http://dx.doi.org/10.1161/01.STR.0000258355.23810.c6

18. Wilson JT, Hareendran A, Hendry A, Potter J, Bone I, Muir KW. Reliability of the modified Rankin Scale across multiple raters: Benefits of a structured interview. Stroke. 2005;36(4):777-81. [PMID:15718510] http://dx.doi.org/10.1161/01.STR.0000157596.13234.95

19. Uyttenboogaart M, Stewart RE, Vroomen PC, De Keyser J, Luijckx GJ. Optimizing cutoff scores for the Barthel index and the modified Rankin Scale for defining outcome in 
acute stroke trials. Stroke. 2005;36(9):1984-87. [PMID:16081854]

http://dx.doi.org/10.1161/01.STR.0000177872.87960.61

20. Muscari A, Puddu GM, Santoro N, Zoli M. A simple scoring system for outcome prediction of ischemic stroke. Acta Neurol Scand. 2011;124(5):334-42. [PMID:21241255] http://dx.doi.org/10.1111/j.1600-0404.2010.01479.x

21. Urwyler SA, Schuetz P, Fluri F, Morgenthaler NG, Zweifel C, Bergmann A, Bingisser R, Kappos L, Steck A, Engelter S, Müller B, Christ-Crain M, Katan M. Prognostic value of copeptin: One-year outcome in patients with acute stroke. Stroke. 2010;41(7):1564-67. [PMID:20508186]

http://dx.doi.org/10.1161/STROKEAHA.110.584649

22. Hallevi H, Albright KC, Martin-Schild SB, Barreto AD, Morales MM, Bornstein N, Ifejika NL, Shuaib A, Grotta JC, Savitz SI; VISTA Investigators. Recovery after ischemic stroke: Criteria for good outcome by level of disability at day 7. Cerebrovasc Dis. 2009;28(4):341-48.

[PMID:19628935] http://dx.doi.org/10.1159/000229552

23. Nijland RH, van Wegen EE, Harmeling-van der Wel BC, Kwakkel G; EPOS Investigators. Presence of finger extension and shoulder abduction within 72 hours after stroke predicts functional recovery: early prediction of functional outcome after stroke: the EPOS cohort study. Stroke. 2010; 41(4):745-50. [PMID:20167916] http://dx.doi.org/10.1161/STROKEAHA.109.572065
24. Lang CE, Wagner JM, Edwards DF, Dromerick AW. Upper extremity use in people with hemiparesis in the first few weeks after stroke. J Neurol Phys Ther. 2007;31(2):56-63. [PMID:17558358]

http://dx.doi.org/10.1097/NPT.0b013e31806748bd

25. Thrane G, Emaus N, Askim T, Anke A. Arm use in patients with subacute stroke monitored by accelerometry: Association with motor impairment and influence on self-dependence. J Rehabil Med. 2011;43(4):299-304.

[PMID:21347506]

http://dx.doi.org/10.2340/16501977-0676

Submitted for publication September 24, 2012. Accepted in revised form January 23, 2013.

This article and any supplementary material should be cited as follows:

Gebruers N, Truijen S, Engelborghs S, De Deyn PP. Predictive value of upper-limb accelerometry in acute stroke with hemiparesis. J Rehabil Res Dev. 2013;50(8):1099-1106.

http://dx.doi.org/10.1682/JRRD.2012.09.0166

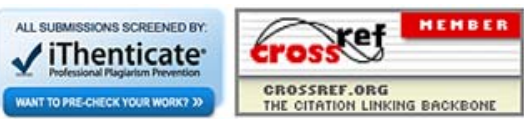

